\title{
IMPLICIT NOTIONS OF IDENTITY: THE ABSENCE OF EXPLICIT COMMUNICATION IN KOREAN HYBRID GREETINGS ${ }^{1}$
}

\author{
Nociones implicitas de identidad: la ausencia de comunicación explícita \\ en los saludos hibridos de los coreanos
}

Wonjung Min*

\begin{abstract}
This study aims to explore the meanings of the manners of contemporary hybrid greetings in Korean culture. In English, manners are defined as a way of behavior and/ or polite ways of social conduct. In contrast, Koreans understand "manners" [ye-jeol] to imply "behaving with discipline" and/or "behaving moderately" in everyday life. After the unavoidable impact of Western influence and Westernized Japanese invasions during the 19th and 20th centuries, Koreans gradually hybridized their customs beginning with greetings. However, can these hybrid customs totally exclude their traditional way? How is Confucianism reflected in contemporary Korean greetings? How can Confucian-based Korean hybrid greetings be explained by High and Low Context Culture Concepts? Korea can be considered a Korean style high-context society due to its long history as a relatively homogeneous ethnic group. Koreans have a high level of communication based on shared contexts. Global greetings are implemented in everyday life as well as in international environment and apparently, Koreans handshakes and body language appear standardized. Still traditional cultural characteristics are expressed in today's greetings. This paper will analyze Confucian-based implicit expressions in greetings

1 This work was supported by the Chilean National Fund for Scientific and Technological Development under Grant Fondecyt No 112015: "Cultural Differences in Greetings between Chile and Korea We Need to be Aware of."

* Instituto de Historia y Centro de Estudios Asiáticos, Facultad de Historia, Geografía y Ciencia Política, Pontificia Universidad Católica de Chile. Santiago, Chile. Correo electrónico: wonjung min@uc.cl
\end{abstract}

Artículo recibido el 13 de abril de 2016. Aceptado el 12 de mayo de 2016. 
through four meaningful behavioral concerns: taking initiative; physical contact; eye contact; and terms of address.

Keywords: Korean hybrid greetings, Confucianism, High Context Culture, Identity.

\section{RESUMEN}

Este studio tiene objetivo de explorar los significados de las costumbres contemporáneas de los saludos híbridos en la cultura coreana. En inglés, los modales se definen como una forma de comportamiento y/o formas de cortesía de conducta social. En contraste, los coreanos entiende los "modales" [ye-jeol] como algo que implica "comportarse con disciplina" y/o "comportarse moderadamente" en la vida cotidiana. Tras el inevitable impacto de la influencia occidental y las invasiones de Japón occidentalizado durante los siglos XIX y $\mathrm{XX}$, los coreanos gradualmente hibridaron sus costumbres en un principio de los saludos. Sin embargo, ¿Pueden estas costumbres híbridas excluir totalmente la forma tradicional? ¿Cómo se refleja el confucianismo en los saludos de los coreanos contemporáneos? ¿Cómo pueden los saludos híbridos coreanos basados en el confucianismo explicarse por el alto y bajo contexto de los conceptos de cultura? Corea puede considerarse como una sociedad de alto contexto al estilo coreano debido a su larga historia con un grupo étnico relativamente homogéneo. Los coreanos tienen un alto nivel de comunicación basado en los contextos compartidos entre ellos. Los saludos globales son implementados en la vida cotidiana así como el entorno internacoinal y aparentemente, los apretones de mano y el lenguaje corporal coreanos aparecen estandarizados. Aún, las caracteríscias culturales tradicionales se expresan en los saludos de hoy en día. En este trabajo se analizarán expresiones implícitas basadas en los saludos a través de cuatro temas de comportamiento significativos: tomar la iniciativa, contacto físico, contacto visual y denominación.

Palabras clave: Los saludos híbridos en la cultura coreana, el Confucianismo, cultura de alto contexto, identidad.

\section{INTRODUCTION}

This study aims to explore the meanings of the manners of contemporary hybrid greetings in Korean culture to help clarify the plural readings in intercultural encounters that can be attributed to their Confucian tradition ${ }^{2}$ and the country's

\footnotetext{
${ }^{2}$ Ironically, Kong fu Zen, renamed Confucius by Jesuit missionaries, was a Chinese civil servant who lived during the Warring States Period about 2,500 years ago. He sought to determine ways in which Chinese society could move away from fighting among themselves so that through discipline, human relationships, ethics, politics, and business they could interact harmoniously. There are different schools and interpretations on Confucianism depending on time and scholars. Among the
} 
recent historical evolution. In English, manners are defined as a way of behavior and/or polite ways of social conduct. In contrast, Koreans understand "manners" [ye-jeol] to imply "behaving with discipline" and/or "behaving moderately" in everyday life. After the unavoidable impact of Western influence and Westernized Japanese invasions during the 19th and 20th centuries, Koreans gradually began hybridizing their greeting customs. However, can these hybrid customs totally exclude their traditional original meanings? How is Confucianism reflected in contemporary Korean greetings? In his book Confucianism and Korean Thought, Keum (2000) emphasizes the importance of Confucianism to understand Korean culture. In their article on Korean corporate culture, Cho and Yoon (2002) indicate that Confucian relationships based on Five Codes are assumed to be unequal. Chen and Chung (1994) suggest that Confucian hierarchy is also reflected in organizational practices.

How can Confucian-based Korean hybrid greetings be explained by Hall's High and Low Context Culture concepts? Korea can certainly be considered a Korean style high-context society due to its long history as a relatively homogeneous ethnic group. Koreans have a high level of communication based on shared contexts; therefore, Cho and Yoon argue that Koreans communicate implicitly because of their strong sense of tradition and preference to let the culture explain rather than words ${ }^{3}$. Global greetings are found more frequently in everyday life in Korea as well as in international environments and, apparently, Koreans' handshakes and body language appear to be standardized. However, traditional cultural characteristics are still expressed in contemporary greetings.

applications of Confucian ideas, Moran, Harris \& Moran's summary on Confucianism is directly related to this article as "a set of practical principles and ethical rules for daily life. ... Confucius taught that people should be educated, skilled, hard-working, thrifty, modest, patient, and unrelenting in all things. Human nature is assumed to be inherently good, and it is the responsibility of the individual to train his or her character in these standards of behavior." (2007: 386).

${ }^{3}$ Moran, Harris \& Moran noted that in only $10 \%$ of 191 nations are the people ethnically or racially homogeneous. According to Fearon (2003)'s research on ethnic and cultural diversity by country, both North and South Koreas have the lowest ethnic fractionalization and cultural diversity with scores of 0.004 and 0.002 , respectively (217). UNESCO has warned Korea against overstressing homogeneity. Also, some anthropologists say that "the pure Korean blood" doesn't make sense at all. It is true that Korea had been attacked by other people about 3,000 times and it was impossible to maintain a single line since it has various races and blood lines. Furthermore, today, Korea's population includes people of various races from 126 countries. However, O-young Lee, honorary chair professor of Ewha Academy of Advanced Studies said that Koreans needed a strong national identity under the Japanese Occupation, stressing that Koreans are a homogeneous people. The division of the two Koreas has also driven Koreans to emphasize that they are analogous people (Kang, Shin-woo. The Korea Times, December 22, 2008). 
Confucian-based implicit expressions in greetings will be analyzed through four meaningful behavioral concerns: taking initiative, physical contact, eye contact, and terms of address. Among the various greeting forms in Korea, in addition to handshaking, such as bowing, kneeling on the floor, etc. only the greeting forms used in international professional and business environments will be discussed in this paper.

\section{TWO DIFFERENT CULTURAL APPROACHES}

People cannot always be expected to rely only on rational judgment to communicate with each other and to express their feelings, emotions and empathy and/or lack of it. Rather, they learn to formalize communication through systematization which accommodates to maintaining the nation/state or culture's social order. People do not seek to achieve indiscriminate agreement, ignoring the various differences of human relationships either. Instead they feel the need to seek social harmony by respecting each one's role. In human relationships people need to follow a proper form of conduct which has already achieved social consensus through the systematized social order. If the law is considered an institutional mechanism to keep the systematized social order, etiquette and/or manners can be considered the daily life mechanism to establish social consensus among the members of society. In all cultures well-mannered people refers to those who relate well with others using smooth communication skills.

However, how are communication skills understood in the world by different cultures? In Korea it is natural for students to bow to the professors when they meet them to show their respect. It may not be natural in other countries but it does not mean that those countries lack respect if they do not bow in such situations. They just have different communication skills and behavior which depend on their different cultural codes. Such communication skills called etiquette and/or manners begin with considering and learning how to relate with other people. McMahon describes both of these terms as follows:

Etiquette and manners are both critical to functioning in society. While both of these concepts involve rules of behavior, they are slightly different, and they involve different types of skills. They also vary from culture to culture, as standards of conduct are heavily based on cultural tradition and heritage. The primary distinction between etiquette and manners is that the first includes specific rules of conduct, while the other is more generalized. Manners involve general behavioral guidelines, such as treating the elderly with respect and courtesy. Etiquette is a specific code of behavior, with an example of etiquette being knowledge of the proper mode of address for a 
queen, which is, incidentally "Your Majesty."... Both etiquette and manners rely on basic underlying principles which include treating people with respect, being sensitive to social situations, and making other people feel comfortable (para. 2).

Originally etiquette meant 'tag' or 'ticket' in the Medieval European Court, where proper etiquette was necessary to determine the protocol or order for individuals to participate in any ceremony. This tradition became the origin of today's etiquette. Similarly, in Eastern culture, high class manners became as commonplace as etiquette is today. In his article about Korea's modernization during the Colonial Period, Shin (2006) insisted that “... culturally, modernization implies a revolutionary change from an elitism centered on an aristocracy to a modern national culture centered on the common man" (441).

Still, the meaning of manners and etiquette is different depending on the culture where they are used, as Smith said above. The Oxford dictionary defines manners as "a person's outward bearing or way of behaving toward others; polite or well-bred social behavior" and etiquette as "the customary code of polite behavior in society or among members of a particular profession or group." In a Confucian society like Korea, etiquette weighs more than the relationship among members of the society. The Korean term Ye implies etiquette as well as manners. It encompasses the moral norm as well as cultural practice. Also, Ye means Confucian ritual of configuration and procedures. However, the Ye is not an immutable law, but a wisdom of moderation appropriately practiced, not insufficient nor overflowing. While the $Y e$ is based on the Confucian traditional moral concept, Yejeol is a system of rules and practices that regulate people's behavior according to their social status.

What do Yeand Yejeolmean to Korean people in contemporary society? Crane, in Korean Patterns, described Koreans as "among the most naturally polite people one will meet when the proper rules of etiquette are followed." He added that "In the remotest mountain village, one will find gracious manners practiced unconsciously. Etiquette is observed in the humblest home as well as in the compounds of the great" (1978: 51). Kim also explained that "Koreans are known to be polite, kind, and humble to others.... Even if one's accomplishments are outstanding, one has to show humility, [because it] is regarded as a virtue and ideal pattern in traditional Korean society" (2007: 271). Cornelius Osgood (1951), the first Western anthropologist who conducted anthropological field work in Korea, described Koreans as passive and inner-directed (331). Edward Poitras (1978) argued that such inner-directedness has encouraged Koreans' strong attachment to their home country, to the point that they might even remain "aliens" rather than become citizens of their new countries when they emigrate (23-35). Even Korean scholar Gyutae Lee (1981) insisted, in his 2 volumes Hanguginui uisik gujo [Structure of the Korean Thought Patterns], that inwardness is the core of Korean cultural patterns. 
Then, should the meaning of polite in the Oxford dictionary and in Korean politeness in Crane's article be understood as the same or just similar? Did the term polite mean the same in 1978 as it did decades earlier and as it does in today's Korea? As Kim (2007) explained, a humble attitude and humility were considered assets rather than liabilities in traditional Korean society. However, he also pointed out three changing factors in Korea as the society became more competitive: from politeness and humility to the "Can-do Spirit" of self-confidence, from inward worldview to outward effort, and from prohibitive norm-oriented patterns to permissive norm-oriented ones (271-275). Due to the fact that Korea is no longer "a small and mutually understanding society where everyone knows everyone else" (272), people have been required to develop an assertive and self-confident attitude. I attributed this transformation to the post-Korean War society in Korea which obliged people to meet the challenge as their only alternative and the dictatorship's probable significant role in the identity formation (2012:268), which is supported by Kim's idea that "can-do spirit" was inspired by President Park Chung-hee and that the self-confidence emerged with Korea's rapid economic development during his presidential term (272) ${ }^{4}$. Redfield (1978)'s article "The Folk Society" declared that traditional society norms in Korea are prohibitive or constraining, but in a modern society they become more permissive by providing alternatives (299). As Kim recently reiterated "many Koreans of the old generation vividly remember that they were taught under the strict rule of prohibitive norms, such as "don't do this" or "that is not to be done"” (1947: 273).

No matter how much traditional patterns may have disappeared or changed, old customs still remain, somewhat modified and somewhat newly interpreted. Greeting manners are one of the examples which express this transition. Western style handshaking is generally understood as greetings between men and women, as well as between men. However, when one sees how Korean people greet each other today, it is not difficult to perceive the difference in age and position between both parties. The younger and lower-positioned parties slightly bow their head when they shake hands with the older and higher-positioned parties, sustaining the right hand with the left hand. When the younger and lower-positioned party greets the older and higher-positioned party without handshaking, the former usually greets bowing the head until the latter simply nods the head to express recognition and acceptance of the greeting. This manner of greeting provides evidence of the fact that Confucianism still has a strong presence in Korea. In fact, the Confucian tradition in Korea is said to be now the strongest in Asia. I would say that in Korea, Confucianism continues to work as a cultural grammar that regulates the Koreans'

\footnotetext{
${ }^{4}$ Lee (1999) also described Korea's fast-growing economy as having created cultural changes resulting in a transformation from a face-saving culture to a modern culture.
} 
customs and consciousness. Kohls (2001) considered that "anyone who wants to study Confucianism in daily life today would be well advised to go not to China or Japan, but to South Korea, where Confucianism is still very much alive” (38).

In an article on global capitalism and Confucianism, Arif Dirlik (1995) pointed out that "unlike many other spiritual traditions, the Confucian focus is [on] the multi-dimensional concerns of the person as a center of relationships" (255). It is questionable whether Confucianism can be considered a spiritual tradition or not. However, Dirlik grasped the essence of the Confucian focus, i. e., the person as a center of relationships. Confucianism defines Five Codes or Five Relations, which are: ruler and subject, parent and child, elder brother and younger brother, husband and wife, and friend and friend. Focusing on a feminist appropriation of Confucianism, Rosenlee (2010) clarified that although "the Confucian world is hierarchical in nature including friendship, the assumed hierarchy in friendship is not gender-based" (186). Nevertheless the scheme of Confucian human relations is complementary and reciprocal because "inequality [is] based on ability or moral authority ... rather than an absolute equality without qualification. One is neither definitely socially inferior nor superior, and each relation is premised on complementarity and reciprocity instead of absolute domination and submission" (185). Even though the manner of cultural expressions in contemporary Korea might differ from ancient times, these fundamental Confucian concepts still dominate the Koreans' thought patterns and represent the moral values they share and by which they live and naturally assume their responsibility for each other.

\section{HIGH \& LOW CONTEXT CULTURE OVERLAP}

Hall ([1977], 1989) explained his idea about cultural context in Beyond Culture in the following words:

...what gives man his identity no matter where he is born is his culture, to total communication framework: words, actions, postures, gestures, tones of voice, facial expressions, the way he handles time, space, and materials, and the way he works, plays, makes love, and defends himself. All these things and more are complete communication systems with meanings that can be read correctly only if one is familiar with the behavior in its historical, social, and cultural context (Hall, 1977: 42).

Hall (1977) introduced High \& Low Context Culture concepts to analyze "how different kinds of extensions work and the influence they exert upon all of us" (39). His High \& Low Context Culture concepts are one of the most 
dominant theoretical frameworks for interpreting cultural differences along with Geert Hofstede's theory of power distance, which will be discussed later. Hall believed that the problems of understanding and interpreting culture "lie not in the linguistic code but in the context, which carries varying proportions of the meaning" (86). He defined High \& Low Context Culture as follows: "A High Context (HC) communication or message is one in which most of the information is either in the physical context or internalized in the person, while very little is in the coded, explicit, transmitted part of the message. A Low Context (LC) communication is just the opposite; i.e., the mass of the information is vested in the explicit code" (91).

Although Hall explained cultures could be arranged on a continuum from extremely LC to extremely HC cultures, some critics found fault with his theory. For example, Cardon (2008) feels that though Hall had provided numerous anecdotes of different cultures he did not describe how he conceptualized or measured these rankings (402). Gudykunst et al.'s (1996) article on influence of cultural values on communication styles across cultures developed an instrument to measure the level of contexting and hypothesized that cultural collectivism and individualism would relate to the HC and LC, respectively. Their instrument referred to measuring inference, indirectness, sensitivity, dramatics, feelings, openness, precision, and silence. Based on these measurements, they developed eight hypotheses:

H1. Members of LC cultures are more likely to have an ability to infer indirect messages of others.

$\mathrm{H} 2$. Members of $\mathrm{HC}$ cultures are more likely to be sensitive to others' feelings.

$\mathrm{H} 3$. Members of HC cultures are more likely to use indirect communication.

H4. Members of LC cultures are more likely to display dramatic communication. H5. Members of LC cultures are more likely to be aware of their own feelings toward others.

H6. Members of LC cultures are more open to disclosing personal information. H7. Members of LC cultures are more likely to use precise communication.

$\mathrm{H} 8$. Members of $\mathrm{HC}$ cultures are more likely to value silence.

Their study was based on a survey done with university students in the USA, Australia, Japan and Korea. They anticipated significant differences between the two culture types based on Hall's theory. But only three of the eight hypotheses ( $\mathrm{H} 1, \mathrm{H} 4$, and $\mathrm{H} 6$ ) were supported, four hypotheses $(\mathrm{H} 2, \mathrm{H} 3, \mathrm{H} 5$, and $\mathrm{H} 7)$ were insignificant and H8 was significant, but it was not supported (Cardon, 2008: 405). Significant as these results may be, it is worth noting that their research was limited to a university student survey. Gudykunst et al. concluded that contexting was better explained on an individual rather than a cultural level. Despite certain 
limitations of Hall's theory and some criticisms about his research, Korea's changing cultural characteristics should be analyzed according to both $\mathrm{HC}$ and LC concepts. Therefore, this paper applies both HC and LC concepts, because HC characteristics are evidently shown in Korean greetings in business environments, which are considered the most global or relatively more westernized occasions of intercultural greetings.

Focusing on relationships, hierarchy/rank/status, elders, formality and indirectness/ritual/"face" seem to coincide very well with Korean $Y e$ and Yejeol concepts. Ye is based on the Confucian traditional moral concept and Yejeol is a system of rules and practices that regulate people's behavior according to their social status. It also reminds us of the "inner-directedness" pointed out by Osgood, Poitras and Lee.

Still Hall recognizes some possible limitations of Western anthropological cultural classification:

In constructing their models of culture, most anthropologists take into account that there are different levels of behavior: overt and covert, implicit and explicit, things you talk about and things you do not. Also, that there is such a thing as the unconscious, although few are in agreement as to the degree to which the unconscious is influenced by culture. The psychologist Jung, for example, hypothecated a "collective" unconscious that was shared by all mankind (a concept many anthropologists might have trouble accepting). Paradoxically, studying the models that men create to explain nature tells you more about the men than about the part of nature being studied. In the West, people are more concerned with the content or meaning of the model than they are with how it is put together, is organized, or performs, and the purpose it is supposed to fulfill (14).

Hall argues that anthropologists tend to make culture patterns "that make life meaningful and really differentiate one group from another" (14). He thinks that the nature of the communication is determined by the level of context. Also he seems to accept sociolinguistic research on how context-dependent the language code is (92). The importance of Hall's HC and LC concept considers historical, social and cultural contexts in order to understand correctly the complete communication systems as cited above. However, Hall admitted that "Context, in one sense, is just one of many ways of looking at things" (113).

Social changes are much more rapid today and global flow permits the whole world's unpredictability as well as of one society's changing characteristics. For example, as I argued in an earlier work, Korean society shows combinations of HC and LC concepts. Hall considered Korea to be a HC Culture, but today's human relations in Korea have more rapid beginnings and closings as LC Cultures do, as Gudykunst et al. showed. Although accuracy is valued, at the same time 
speed is also appreciated. Social connections now tend to be stronger among professionals than among the families (Min, 2012: 268).

\section{IMPLICIT EXPRESSIONS IN GREETINGS}

Korean hybrid greeting styles show how meaningful the implicit expressions are, especially regarding taking initiative, physical contact, eye contact and choosing the proper terms of address. How can polite greetings in Korea be described? There have been several studies on politeness according to the researchers' interests. They recognize that what is polite in one culture may not be considered polite in another culture because politeness is culturally relative. Lakoff $(1973)^{5}$ pointed out, in an article on the logic of politeness, that conversational etiquette conveys politeness since politeness is essentially the avoidance of friction in communication (292305). According to Haverkate's pragmatic linguistic study of verbal courtesy (1988, 1994), conversational etiquette is based on three wise recommendations: No hables gritando ni susurrando, no interrumpas al que está hablando y presta atención a lo que dice tu interlocutor [Don't scream nor whisper, don't interrupt the person who is talking and pay attention to what the person is saying to you] (author's translation, Haverkate, 1994: 63).

In order to compare linguistic and nonlinguistic politeness in Korea and the USA Ambady et al. (1996) adapted Brown and Levinson's (1987) positive and negative categories of politeness strategies in language usage. Ambady et al. videotaped interactions of role playing in given situations, such as to give good and bad news to a superior, subordinate and peers in the work place. Brown and Levinson's classification of positive politeness strategies included being "affiliative, attentive, concerned, approving, encouraging, supportive, empathic, emotional, and positive; seeking agreement; and joking." Their categories of negative politeness included being indirect, not being open, being apologetic, minimizing the imposition, and being uncertain, professional, and deferential." (1001). Ambady et al.'s three composite variables: affiliative, circumspect and other-oriented strategies, were created to combine both positive and negative strategies and "to define strategies that were more specific, ecologically valid, and situationally relevant to [their] study" (1010) through their research. Although Brown and Levinson considered all politeness to be oriented toward others, Ambady et al.'s analysis

\footnotetext{
${ }^{5}$ Lakoffs (1973) seminal work on politeness has been considered the foundation work on modern politeness theory. (Mahyuni 2008: 116). Lakoff (1990) defines politeness as: “... a system of interpersonal relations designed to facilitate interaction by minimizing the potential for conflict and confrontation inherent in all human interchange" (34).
} 
separated other-orientation from affiliation and circumspection to consider both verbal and non-verbal communication.

The principal-components analysis addressed the exploratory question about the kinds of strategies individuals use when nonlinguistic channels are taken into account. The typology of strategies showed a considerable amount of overlap with the structure of linguistic strategies proposed in politeness theory. Affiliativeness and circumspection consisted of positive and negative politeness strategies, respectively. Although other-oriented strategies consisted of a mix of both positive and negative strategies, this result is consistent with past research suggesting that the delineation of positive and negative strategies may not be clear cut and that individuals tend to use a mixture of both types of strategies (Craig et al., 1986; Lim and Bowers, 1991; Scollon \& Scollon, 1983, quoted in Ambady et al., 1002).

Affiliative strategies consisted of positive politeness strategies, such as being open, affiliative, and joking. Circumspect strategies consisted of negative politeness strategies such as being uncertain, avoidant, apologetic and indirect. Other-oriented strategies consisted of attentive, concerned, seeking agreement, encouraging, polite, approving, deferential, positive, empathic, and professional (Ambady et al., 1002). Their observations showed that "Koreans and Americans used the strategies of affiliation and circumspection similarly, but they differed in the manner in which they used the strategy of other-orientation" (1007). Ambady et al.'s research found that "although Americans and Koreans weighed power and distance differently in their politeness strategy usage patterns, politeness theory provided a valid explanation of strategy usage in both cultures" (997).

Koreans are noticeably other-oriented in human interaction. However other-oriented human interaction in the concept of politeness can be understood differently in different cultures due to their specific cultural codes. In research on cross-cultural differences in approach-avoidance communication in South Korea and the US, Rebecca Merkin (2009) argues as follows:

The high-context South Koreans need to obscure meanings to militate against shame ... that South Korean citizens are more likely to be communicatively apprehensive about intercultural interactions than their US American counterparts. This is because shame is attributed to communication itself. There is a profound high-context distrust of communication itself which leads South Koreans to avoid explicit intercultural communication. If a message's meaning is unclear, the shame cannot be realized. Thus, it is likely that the nervousness that accompanies their fear of shame could be expressed through a heightened intercultural communication apprehension (208). 
Like Lee and Kim, she also admits that South Korea's fast-growing economy led society's transformation from a face-saving culture to a more individualistic culture (201). Yet the traditional Confucian-based mentality and attitude toward interpersonal relationships still remain therefore, being polite in Korea requires being other-oriented. Korean politeness requires paying attention to what the speaker is saying to the counterpart after the appropriate form of greeting has taken place.

In this sense, the concept of Confucian hierarchy must also be understood correctly. Of course, age is important in Korean culture; however, it is commonly used in general relationships or among those of the same status. In the workplace, social status may have more priority than one's age, but age can never be ignored. Therefore, the younger and/or the lower-positioned-people greet older and/ or higher-positioned people. When the relationship between age and status is ambiguous, both greet at the same time. When it is difficult to determine age and status, the one who greets first is generally considered a polite person. However, greeting first does not mean taking initiative in Korean greetings. Greeting before the older and/or higher-positioned implies showing respect for their age and position. Also, the pronounced or slight angle of bowing one's head may reveal either the importance attributed to the receiver's position or the greeting sender's degree of respect.

The gesture of bowing one's head often goes with shaking hands. When one just bows, the younger and lower-positioned party appears to begin the greetings and the older and higher-positioned party just acknowledges the bow with a slight nod. However, that bow is the younger and lower-positioned party's response to the counterpart's implicit expectation. In contrast, in order to shake hands, the older and higher-positioned party must start while the younger and lowerpositioned counterpart receives the extended handshake with a respectful bow. In both cases initiative is understood to be taken by the older and higher-positioned party, even when that initiative is no more than the implicit expectation that the lower-positioned party recognizes or acknowledges. When bows accompany handshaking, the younger and lower-positioned one's left hand supports the right hand, as mentioned before. Professional women also shake hands. According to a Korean etiquette handbook, in the case of handshaking, women, older and higherpositioned and married people should ask for the handshake by extending their hand to men, younger and lower-positioned and un-married people. The Head of State and religious leaders are exceptional cases permitted to initiate a handshake. Although the handbook allows women to initiate a handshake in Korea as well as in the Western world, such initiative seldom occurs because Korean older and higher-positioned men still tend to take initiative in handshaking. Women are not expected to shake hands with each other. Handshakes between men and women 
are not as frequent as between men. Bows go at the beginning and at the end of the meeting. Among friends, people just wave.

Handshakes may be the closest physical demonstration between men and women in Korea when they have no filial or romantic relationship. Even in filial relationships and among close friends there are no kisses or hugs in greetings. Koreans consider physical contact as if it were a personal violation to be touched by anyone who is neither a relative nor close friend. On the other hand, girls often hold hands among friends of the same sex, but this does not cause any sociocultural misunderstanding in Korea. Still, friends just wave their hand when they meet and separate. Explicit greetings are seldom observed among family members, who usually just acknowledge each other with eye contact and/or a slight nod, but without kissing or hugging or even waving. Therefore, one can state that physical contact is considered inappropriate with older and higher-positioned people, people of the opposite sex and/or people who are not close friends nor family. Nevertheless, older and higher-positioned people may often greet the younger and lower-positioned with a pat on the back or shoulder as a sign of praise or encouragement.

Instead of interchanging greetings with kisses and hugs, eye contact is always more significant than direct physical contact. The ability to grasp the meaning of invisible implicit messages at first sight almost determines the future relationships. The older and higher-positioned party sends his eye message of expectation to the younger and lower-positioned party who should then initiate the appropriate greeting as soon as he/she detects the former's eye signs. However, direct eye contact between junior and senior businessmen should be avoided because it may be understood as impolite or even as challenging the authority. Therefore, some Koreans have difficulty in maintaining steady eye contact with an authority in international business environments. Men also tend to avoid eye contact with women.

Terms of address in the Korean language also express the Confucian concept of unequal status in all relationships (Cummings, 1997; Kohls, 2001). One's title varies and is determined by each one's social status, depending on the relationships involved in the workplace, among family, friends or neighbors. For example, Mr. Kim, Mrs. Lee, Professor Choi, Dr. Park, President, Ambassador, (son and/or daughter's name)'s mom, etc. reveal the social status. This title in the terms of address reveals the hierarchical relationships between both parties. The title is determined by age as well as social status. Verb conjugation differs for each level of formality and sometimes different choices of vocabulary are required, again depending on the age and social status of the "addressee" to whom one is speaking and or bowing. But one never uses an honorific title for oneself such as "I am Mr. Kim." One is expected to lower oneself with modesty when addressing to the elder 
and higher-positioned party, but may talk down to younger and lower-positioned parties. If the lower-positioned party is older than the higher-positioned party, the latter uses a more formal semi honorific term of address to the former, indicating the person's title or social position. The title which symbolizes one's social status is more used than one's name, and also the title goes with one's family name or full name rather than one's given name. Due to the need to identify each one's social status, Koreans often pass their name cards with both hands as an expression of respect when they greet others for the first time. A sign of respect is always expected in greeting older and higher-positioned people and in official business relations.

Often, when one is going to greet an older or higher-positioned Korean, it is better to ask about his/her health as the most appropriate greeting. And when meeting one's son's friend, the appropriate or expected Korean greeting is to ask about his parents' health and then often to ask if he has eaten, instead of saying good morning, afternoon or evening. These are some expressions that reveal the Koreans' concern for the others who are related to the receiver of the greeting because those others determine who the receiver is. Social status does not necessarily refer to one's social class, but rather to the group and/or occupation to which one belongs. As described above, the silent implicit message is even more used among close relationships and/or elder and of higher social position. Koreanstyle time-oriented greetings do not refer to good morning, good afternoon, and good evening but instead ask "Have you eaten breakfast/lunch/dinner?" usually without expecting an answer. To the question "How are you?' there is no "and you?" style answer. Two greeting parties just ask "How are you?" simultaneously to express "Hello" and no answer is expected (Min, 2012: 267).

\section{THE NOTION OF KOREAN IDENTITY IN GREETINGS}

Hall's descriptions of HC and LC Culture concepts are mainly based on his observed differences in dimensions of interest in social bonding and are attributed to the contextual tendencies of the culture in the late 1970's. Coincidentally, his ideas seem to share certain proximity to Confucianism, though his contextual focus requires more meaningful interpretation of the implications of the cultural differences. HC and LC Culture concepts are one of the attempts to measure cultural differences, but one cannot always trust and apply them due to the syncretic hybridization of cultures caused by the increasing flow of globalization over the past century. Korea is considered to be a HC Culture by Hall's theory and it is partially true. However, as Jane Thomas (1998) admitted in "Contexting Koreans" that South Korean managers at the global company certainly show Low Context Culture styles (9). She found that South Koreans communicate with a 
low-context emphasis on relationships, choosing direct organizational patterns with deductive lines of reasoning, just like the more individualistic US Americans. Kim et al. (1998) did interesting comparisons of HC and LC Culture in Chinese, Korean and American cultures. They focused on six aspects of Hall's theory such as social orientation, commitment, responsibility, confrontation, communication and dealing with new situations. Social orientation measures the depth of involvement in relationships. The degree of commitment is shown by completing one's words with action. Responsibility in $\mathrm{HC}$ culture is assumed by the highest level of top-down decision-makers who are responsible for their subordinates, while responsibility is diffused in LC culture throughout the system. Confrontation refers to how aggression is handled: Face-saving in HC culture is to reduce conflict and preserve harmony, while conflict is expressed verbally in LC culture. Communication is both verbal and non-verbal expression in relationships: how it is said is more important in HC culture and what is explicitly said is more important in LC culture. Dealing with new situations: $\mathrm{HC}$ culture can be creative when dealing with their old system, while LC culture can be more creative when dealing with new contexts. Kim et al. found that Chinese and Koreans have shown more consistency to Hall's HC Cultures and the Americans to LC Culture. Also, Chinese and Koreans are more socially oriented, more confrontation-avoiding and have trouble dealing with new situations. Still they found that both Chinese and Korean managers revealed a tendency to be quite Westernized due to their frequent business communication with foreign business partners (519).

Focusing on this paper's topic of Korean greeting manners, their form may seem very international or Westernized, but at the same time, they seem to be more typical of HC culture, depending on the observer's point of view. There is no doubt that younger and lower-positioned people start greetings in Korea. But as mentioned before, starting greetings does not mean taking initiative. Instead, it is more related to the degree of self-control, not a sign of exercising power. Starting greetings is above all showing respect, being polite and in Confucian social tradition behaving moderately with discipline.

Starting greetings may appear to be taking initiative and can be misunderstood as "power distance" defined by Hofstede in Culture's Consequence (2001) to explain cultural differences in cultural management or organizational culture. He explains the cultural differences through different power distance in hierarchies: "the power distance norm can be used as a criterion for characterizing cultures (without excluding other criteria)" (84). For him Power Distance is "the extent to which the less powerful members of an organization expect and accept that power is distributed unequally" (98). His research defines Korea as a high power distance country together with other Confucian-influenced countries. However, while human relationships in Confucianism are certainly unequal, they 
are also complementary and reciprocal. Hofstede also admitted that Confucian human relationships "contain mutual and complementary obligations" (114).

Regarding Confucian-based unequal relationships in Korean society, Park and Kim (1992) had confirmed that, for Koreans, "growing old represents signs of grace, respect, and piety, [therefore], age is the first consideration when Koreans communicate with one another" (399). Park and Kim emphasized that the concept of equality hardly exists in everyday interactions in Korea (400). But on the other hand, Lincoln's (2010) research findings revealed that South Koreans indicated a low level of power distance (100). He attributed this more recent behavior to the younger generation's adaptation to more frequent and more extensive contact with other societies. Nevertheless, the younger and the lower-positioned always continue to show their respect for the older and higher-positioned people in greetings.

It may sound contradictory, but in HC cultures, "most communication relies more on the physical context or is internalized in the person, and less information is contained in the verbal part of the message such as in words, sentences, and grammar" (Kim et al., 1998: 512). In other words, one needs to transmit the messages in an appropriate context in order for the right messages to be understood. For outsiders and/or foreigners, it is complicated to understand such intuitive meanings in Korean greetings. Kim et al. found that HC culture people are more concerned about others, as well as the whole society; therefore, social status is more important than personal feelings of self-actualization (514). Who begins greetings? Who bows the head? How does two party handshaking appear to the observers-Korean and non-Korean? All of these non-verbal implicit interactions in greetings reveal the recognition and acknowledgement of the Koreans' age, social status and relationships.

Robinson (1996) pointed out three relevant factors to understand professional communication in Korea, which are nunchi, dualism, and hierarchy. Martin et al. define nunchi as "tact, savoir faire, sense, social sense, perceptiveness and an eye for social situations" (1967). Lee (1983) defines nunchi as follows: "Nunchi, literally eye-measure, is both the feelings and the manners of a person and it is also, in verb form, to study the attitudes and emotions of another person so that you may know how to respond. In the second sense, it is therefore, something like the sizing up of a situation, but it forms a more central core of Korean thought" (28).

He considered "Nunchi" to be a kind of "sense", but it cannot simply be explained as sense" (28). It seems to be more intuitive and sensitive than logical or rational. Still nunchi is a situational ethic used to solve interpersonal problems. Lee also admitted that "intuition developed more than logic, and the sensitivity required to grasp all these signs developed more than reason" (30). Fleischanderl (2005) defines nunchi as “the ability to read a person's gibun (feelings)" (2). 
Koreans' tendency to be concerned about others could be related to Hall's HC culture's "focus on relationships". Furthermore, this Korean focus on relationships is related to Confucian-influenced self-control which may seem similar to Hall's classification of "indirectness" and is necessary to maintain harmony. However, it is important to note that Hall's HC \& LC Culture concepts are logical or rational analysis, while nunchi, Koreans' implicit message, implies more intuitive analysis than logical signs. Fleischanderl admitted that "Logic was an untoward concept in Korea until modern times, and taboo. Even today, the typical Korean is turned off by the obvious and aggressive use of logic" (1). He explained that "From the Korean point of view, a logical mind is generally regarded as disruptive rather than constructive" (1). Disliking explicit logical expression is certainly related to the issue of shame which mentioned before. Confronting insistence on rationality and lack of consideration of human emotion and feelings may embarrass the counterpart. Retzinger (1991) has established shame as the cause of social conflict. According to Scheff and Retzinger (1991), shame is a threat to the social bond (quoted in Merkin 2009: 202). Bailey (1997) described shame as follows: "For example, when someone feels shamed by another, the social bond comes under stress and he/she is likely to avoid communicating to relieve the tension of an interaction developing into a potentially face-threatening situation. In contrast to US American expressiveness, South Koreans and their inner Confucian values practice collective restraint" (quoted in Merkin, 2009: 202).

Koreans certainly tend to give precedence to human factors over facts and logic because this tendency is one of the key factors which enables them to maintain social order and harmony.

Regarding more non-verbal than verbal expressions, Robinson understood that "A negative reaction may be manifested in a face that becomes as expressionless as stone, rather than in some verbal explosion. Expressions of affect are found in the eyes rather than on the face or from the whole body" (129). Such delicate eye expressions are considered non-verbal expressions or more accurately physical eye contact in Korean culture, but those implicit expressions may also provoke ambiguous interpretations for cultures which have more explicit expressions.

Robinson defined dualism and hierarchy as cultural concepts related to nunchi. Nunchi has both positive and negative sides and from both sides, nunchi is used to avoid unpleasantness for oneself by foreseeing the behavior of others and to avoid unpleasantness for others by using deception. The first strategy could be helpful in interactions and the second could be misunderstood as dishonesty and result in negative stereotypes, if not lead to social conflict (130).

Based on his working experience in Korea, Fleischadnerl (2005) characterized Korean etiquette as follows: 
Bowing properly to a superior, using proper formal language and respecting official titles, treating a senior and a subordinate accordingly, and giving an appropriate gift, are practices easily understood and adopted by Westerners. On the other hand, there is etiquette that might make no sense to Westerners and which, on the contrary, is considered as disruptive to an efficient life from a Western point of view. These include hiding bad news, hesitating to make critical remarks about someone or something (that might be contrary to the other party's views), criticizing the competency, veracity, or honesty of an individual, keeping silent about a mistake that has been made, or lying about some matter (1).

Robinson also pointed out that within hierarchical relationships, "interaction is highly ritualized, with great importance placed on the proper behavior and the proper language for both juniors and seniors" (130). This reminds us of the concepts of $Y e$ and Yejeol, i.e. Korean etiquette and manners. Today's Korean implicit expressions in greetings shown in taking initiative, physical contact, eye contact, and terms of address, reveal the hybridization of global handshaking and Confucian-based ritualized form. For both Ye/Yejeol and etiquette/manners, the key issue is still to determine how to relate with others. Even though Korean society has become more competitive through transitions which have led the society to become more self-confident, outward and permissive normoriented, still, politeness, humility, and inwardness have not and cannot disappear in Korean greetings because of their traditional Confucian-based ritualized values.

Descriptions and analyses of Korean identity published as empirical research findings may seem to contradict Hall's and other researchers' conceptions, but the sum total of their diverging positions may be considered as evidence of the hybridization of the cultural context in constant transition. Findings depend on each researcher's discipline and time of the historical focus, as well as each individual's interpretation of actions in real life and time.

While both Western and Korean greetings reveal fundamental respect for each other and value polite expression, the underlying concept in Western greetings is that of equality in relations. However, the underlying traditional Confucian concept in Korean greetings is that of unequal, as well as complimentary and reciprocal relationships. For Koreans the explicit inequality implies implicit complementarity and reciprocity as fundamental representations of their identity in constant transition. 


\section{REFERENCES}

Ambady, Nalini, Koo, Jasoo \& Rosenthal, Robert. "More than Words: Linguistic and Nonlinguistic Politeness in Two Cultures", Journal of Personality and Social Psychology 70/5 (1996): 96-1011. Avalaible in: http://ambadylab. stanford.edu/pubs/1996Ambady.pdf.

Bailey, Benjamin. "Communication of Respect in Interethnic Service Encounters", Language in Society 26 (1997): 327-356.

Brown, Penelope \& Levinson, Stephen. Politeness: Some Universals in Language Usage. Cambridge, England: Cambridge University Press, 1987.

Cardon, Peter W. "A Critique of Hall's Contexting Model: A Meta-Analysis of Literature on Intercultural Business and Technical communication", Journal of Business and Technical Communication 22 (2008): 399-428.

Chen, Guo-Ming \& Chung, Jensen. "The impact of Confucianism on Organization Communication”, Communication Quarterly 42/2 (1994): 93-105.

Cho, Yung-ho \& Yoon, Jeongkoo. The Origin and Function of Dynamic Collectivism: An Analysis of Korean Corporate Culture. In Chris Rowley Tae-Won Sohn \& Johngseok Bae (Ed.), Managing Korean Business Organization, Culture, Human Resources and Change. Portland, Oregon: Frank Cass, (2002): 70-88.

Crane, Paul. Korean Patterns. RaS: PF Edition, 1978.

Cummings, Bruce. Korea's Place in the Sun: A Modern History. New York: W. W. Norton \& Company, 1997.

Dirlik, Arif. "Confucius in the Borderlands: Global Capitalism and the Reinvention of Confucianism”, Boundary 2 22/3 (Autumn 1995): 229-273.

Fearsibm James D. "Ethnic and Cultural Diversity by Country", Journal of Economic Growtt 8/2 (June 2003): 195-222.

Fleischanderl, Bernadette. Feelings (gibun), Harmony (hwa), and Intuition (nunchi). Korea Foundation Newsletter 14/4 (November 2005). 
Gudykunst, William B.; Matsumoto, Yuko, Ting-Toomey, Stella, Nishida, Tsukasa; Kim, Kwangsu \& Heyman, Sam. "The Influence of Cultural Individualism-Collectivism, Self Construals, and Individual Values on Communication Styles across Cultures", Human Communication Research 12 (1996): 510-543.

Hall, Edward T. Beyond Culture. New York: Anchor Books (1977, 1989).

Haverkate, Henk. "Towards a Typology of Politeness Strategies in Communicative Interaction", Multilingua 7 (1988): 385-408.

Haverkate, Henk. La cortesía verbal: estudio pragmalingüistico. Madrid: Gredos, 1994.

Hofstede, Geert. Culture’s Consequence. Thousand Oaks, CA: Sage Publications, 2001.

Kang, Shin-who. "Is Korea Homogeneous Country?" Korea Times, August 14, 2008.

Keum, Jang-tae. Confucianism and Korean Thoughts. Seoul: Jimoondang Publishing Company, 2000.

Kim, Choong Soon. Kimchi and IT. Seoul: Ilchokak, 2007.

Kim, Donghoon; Pan, Yigang \& Park, Heung Soo. "High-Versus-Low Context Culture: A Comparison of Chinese, Korean, and American Cultures", Psychology and Marketing 15/6 (1998): 507-521.

Kohls, L. Robert. Learning to Think Korea: A Guide to Living and Working in Korea. Boston: Intercultural Press, 2001.

Lakoff, Robin. "The Logic of Politeness; or, minding your P's and Q's", Nineth Regional Meeting of the Chicago Linguistic Society. Chicago Linguistic Society, IX (1973): 345-356.

Lee, Gyutae. Hanguiginui uisik gujo [Structure of the Korean thought patterns] 2 vols. Seoul: Munrisa, 1981.

Lee, O-Young. In This Earth \& In This Wind, This is Korea. Translated by David I. Steinberg. Seoul: Royal Asiatic Society, Korea Branch, 1983. 
Lee, Zuk Nae. "South Korean Culture and Sense of Shame", Transcultural Psychiatry 36 (1999): 181-195.

Lincoln, Scott. (2010). "The Far Side: Contrasting American and South Korean Cultural Contexts." Asian Social Science 6/12 (December 2010). Available: http://www.ccsenet.org/journal/index.php/ass.

Mahyuni. "The Socio-cultural Significance of Valuing Linguistic Politeness", LINGUISTIKA 15/28 (2008): 115-128.

Martin, Samuel E.; Lee, Y. H. \& Chang, Song-on. A Korean-English Dictionary. New Haven CT: Yale Univ. Press, 1967.

McDowell, Michael. "Native American Literature, High Context and Low Context", PCC (Portland Community College), 2003. Avalaible: http:// faculty.pcc.edu/ - mmcdowel/eng240fall03/eng240highlowcontext.pdf.

McMohan, Mary. (n. d.). What is the Difference between Etiquette and Manners? wiseGEEK. http://www.wisegeek.com/what-is-the-difference-between-etiquetteand-manners.htm.

Merkin, Rebecca S. "Cross-Cultural Differences in Approach-Avoidance Communication in South Korea and the US", Human Communication. A Publication of the Pacific and Asian Communication Association 12/2 (2009): 199-214.

Min, Wonjung. "Cultural Cues in Cross Cultural Communication between Chileans and Koreans to Understand What "Hello" and "How are you?" mean in Chile and Korea." In Wonjung Min (Ed.), Corea un acercamiento multidisciplinario [Korea, A Multidisciplinary Approach]. Santiago, Chile: Pontifical Catholic University of Chile, (2012): 253-270.

Moran, Robert T., Philip R. Harris, and Sarah V. Moran, Managing Cultural Differences. Burlington, MA: Elsevier, 2007.

Osgood, Cornelius. The Koreans and Their Culture. New York: The Ronald Press, 1951.

Park, Myung-seok \& Kim, Moon-soo. "Communication Practices in Korea", Communication Quarterly 40/4 (Fall 1992): 398-404. 
Poitras, Edward W. Maredo seoyeori ita [There is an order even in speech]. In D. Sin Hangugineun nuguinga: Oegugini bon uriui uisik gujo [Who are the Koreans: Structure of the Korean thought patterns seen by foreigners]. Seoul: Chosun Ilbosa, (1978): 29-35.

Redfield, Robert. "The Folk Society", American Journal of Sociology 52 (1978): 293-308.

Retzinger, Suzanne. Violent Emotions: Shame and Rage in Marital Quarrels. Thousand Oaks, CA: Sage Publications, 1991.

Robinson, Jeaninne H. "Professional Communication in Korea: Playing Things by Eye", IEEE Transactions on Professional Communication 39/3 (September 1996): 129-134.

Rosenlee, Li-Hsiang L. A Feminist Appropriation of Confucianism. In Wonsuk Chang \& Leah Kalmanson (Eds.), Confucianism in Context Albany, NY: State University of New York Press, (2010): 175-190.

Scheff T. J. and S. Retzinger. Emotions and Violence: Shame and Rage in Destructive. Lexington, Mass: Lexington Books, 1991.

Shin, G. W. Ethnic Nationalism in Korea. Stanford: Stanford University Press, 2006.

Thomas, Jane. "Contexting Koreans: Does the High/Low Model Work?”, Business Communication Quarterly 61/9 (1998): 9-22. 